\title{
Morphological plasticity in Zostera muelleri across light, sediment, and nutrient gradients in Australian temperate coastal lakes
}

\author{
Angus J. P. Ferguson ${ }^{1, *}$, Renee K. Gruber ${ }^{1,2}$, Michael Orr ${ }^{1}$, Peter Scanes ${ }^{1}$ \\ ${ }^{1}$ New South Wales Office of Environment and Heritage, Sydney, NSW 2000, Australia \\ ${ }^{2}$ Present address: University of Western Australia, Perth, WA 6009, Australia
}

\begin{abstract}
Biomass and morphometrics of Zostera muelleri were monitored across depth, sediment type, and nutrient gradients in 2 coastal lakes (Tuggerah Lakes and Lake Macquarie) on the east coast of Australia. Tuggerah Lakes had significantly higher nutrient, chlorophyll $a_{\text {, and }}$ suspended sediment concentrations in the water column and significantly higher fine sediment fraction and sediment organic matter content. Seagrass above-ground biomass (AGB) was significantly greater in the mesotrophic Tuggerah Lakes, while below-ground biomass (BGB) was significantly greater in the oligotrophic Lake Macquarie, most likely reflecting the different nutrient status of the lakes. Light gradients were the primary control over total biomass, BGB, and shoot density across the study area. Although no general trends between light and AGB were found in this study, lake- and site-specific relationships between light, AGB:BGB ratios, and leaf area index were seen to vary along gradients in nutrient status and sediment quality. These trends are thought to be driven by morphological acclimation that allows seagrass to maintain favourable plant carbon and net community metabolism balances while minimising sulphide exposure. Seagrass depth limits were best predicted by a multilinear model including Secchi depth, fine sediment fraction, and organic matter content, suggesting that negative feedbacks associated with sulphide exposure in the rhizosphere increased the minimum light requirements of this species. Our results support an emerging view that sediment quality and nutrient status are important controls over minimum light requirements in seagrasses. Morphological plasticity can moderate but not completely compensate for the negative impacts of sediment properties on minimum light requirements.
\end{abstract}

KEY WORDS: Seagrass $\cdot$ Morphological plasticity $\cdot$ Depth gradient $\cdot$ Sediment quality $\cdot$ Nutrients

\section{INTRODUCTION}

Seagrass is an iconic biotope in coastal waterways around the world, with recognised ecologically significant roles in coastal food webs (Gillanders 2006), fisheries habitat (Jackson et al. 2001), and as a 'blue carbon' sink (Duarte et al. 2010). Increasing pressure on seagrass environments due to eutrophication, dredging, habitat destruction, and climate change (Orth et al. 2006, Waycott et al. 2009) prompt an urgent need for better qualitative and quantitative

${ }^{*}$ Corresponding author:

angus.ferguson@environment.nsw.gov.au models of seagrass resilience that allow managers to identify site-specific problems and solutions. To date there have been numerous approaches of varying complexity employed to model seagrass, ranging from simple optical models based on light attenuation and minimum light requirements (Dennison et al. 1993) (Gallegos 1994, Cerco \& Moore 2001), to more detailed models that couple temperature, light, and nutrient availability to estimates of productivity, respiration, and biomass fluxes (Harris 2006). Central to all of these models is the concept of minimum light

(C) The authors 2016. Open Access under Creative Commons by Attribution Licence. Use, distribution and reproduction are unrestricted. Authors and original publication must be credited. 
requirements, which have been shown to be speciesspecific, and dependent on sediment conditions such as organic matter (OM) content (Krause-Jensen et al. 2011). The mechanistic reasons underpinning variation in light requirements are still unclear (Kenworthy et al. 2014), making their realistic inclusion in models difficult. In addition, the parameterisation of biomass models (e.g. the rate of transfer of resources between above- and below-ground biomass) is problematic given a likely dependence on environmental conditions (Zharova et al. 2001).

Developing a better understanding of the variation in the biology and physiology of seagrass species in response to environmental stressors is therefore central to improving current seagrass models. One aspect of this variation is the ability of seagrass to phenotypically alter morphological traits (i.e. aboveand below-ground biomass [AGB and BGB, repectively], shoot density, and shoot length), known as 'plasticity' (Vermaat et al. 1996, Peralta et al. 2005, van der Heide et al. 2010). This morphological plasticity allows seagrasses to withstand seasonal changes in environmental stressors (e.g. light, temperature, and nutrient availability) and facilitates seagrass acclimation and persistence over a wide range of environmental conditions (Hackney \& Durako 2004). As such, plasticity may be considered an important aspect of resilience, and an understanding of its limits helps interpret changes in seagrass communities and manage seagrass declines in the short and long term.

Morphological plasticity within a seagrass species is driven by many factors including light climate (Ralph et al. 2007), nutrient status (Perez et al. 1994, Clores \& Santos Carandang 2013), physical stress (Hackney \& Durako 2004), and sediment properties (de Boer 2007'). Plants may alter AGB by modifying shoot density and length (with lesser variations due to width and number of leaves). Decreasing density and increasing length can allow acclimation to lower light climates (Bulthius 1983, Collier et al. 2009) by reducing self-shading effects while increasing leaf area index (LAI). The relative allocation of biomass between above-ground and below-ground tissue (given by the ratio of AGB to BGB) is a primary morphological response to a variety of environmental drivers and internal physiological demands. Plants may downregulate BGB (i.e. increase AGB:BGB) in response to adverse sediment conditions (Hemminga 1998) or upregulate root biomass (i.e. decrease AGB:BGB) to facilitate nutrient uptake in the rhizosphere (Lee \& Dunton 2000b) and stabilize the plant in a hydrodynamically energetic environment (Schanz
\& Asmus 2003). Finally, the AGB:BGB ratio may also be controlled by an internal need for the plant to balance respiratory demands with photosynthetic production (Dennison 1987a). All of these phenotypic responses most likely allow seagrasses to extend their range; however, it is likely that there may be costs and limitations to phenotypic plasticity that will impose limits to plant responses and, ultimately, the extent of their range (DeWitt et al. 1998).

Zostera muelleri ssp. capricorni (Ascherson) S. W. L. Jacobs occurs in Australia across a wide latitudinal range of $30^{\circ}$, from tropical northern Queensland to cool temperate Tasmania. Within New South Wales at the centre of this range, $Z$. muelleri is abundant in 2 neighbouring coastal lakes, the oligotrophic Lake Macquarie and the mesotrophic Tuggerah Lakes. Zostera muelleri displays a wide range of morphologies in the 2 systems, providing an opportunity to explore the relationship between morphological plasticity and environmental conditions within a narrow latitudinal zone. The comparison of seagrass across depth gradients in adjacent lakes of differing nutrient status allows an analysis of natural morphological responses due to light, sediment properties, and nutrient enrichment that is distinct from studies that employ either ex situ or in situ experimental shading and fertilisation (Cayabyab \& Enríquez 2007, Kelaher et al. 2013). In these studies, plants that are (genotypically) selected or (phenotypically) acclimated to one set of environmental conditions are subjected to artificially altered conditions. The resulting changes in morphology or biomass provide important insights into likely trajectories of response to disturbance; however, their ability to describe the morphological plasticity of a species as a whole is limited, as this is likely to arise over a much longer time scale than is commonly employed in such experimental work. Strategically stratified field surveys can complement experimental studies to provide insights into morphological plasticity (Perez et al. 1994, Miller et al. 2005).

The present study describes biomass and morphology in Z. muelleri across environmental gradients of light, sediment grain size, sediment OM content, and nutrient enrichment within 2 temperate coastal lakes on the east coast of Australia. We expect that $Z$. muelleri will display morphological plasticity across these gradients; however, interactions between different stressors may result in complex responses in plant morphology. For example, a decrease in AGB:BGB may be expected in nutrient-limited environments (Lee \& Dunton 2000b); however, light limitation across the depth gradient will cause an 
upward pressure on AGB:BGB (Dennison 1987a). Interactions between co-occurring drivers may obscure generalised trends observed in morphology across environmental gradients, giving rise to the need for more complex models to explain morphological plasticity. We also hypothesise that morphological plasticity in $Z$. muelleri may facilitate the colonisation of environments towards the limits of its range.

\section{MATERIALS AND METHODS}

\section{Study area}

Lake Macquarie (mean depth $8 \mathrm{~m}$; mean flushing time $227 \mathrm{~d}$ ) and Tuggerah Lakes (mean depth $2.8 \mathrm{~m}$; mean flushing time $100 \mathrm{~d}$ ) are located on the New South Wales central coast, approximately $85 \mathrm{~km}$ north of Sydney (Fig. 1) (Watterson et al. 2010). The region experiences a warm temperate climate, with most rainfall occurring in late summer and autumn. Both lakes are connected to the ocean via narrow entrances that are maintained permanently open. Zostera muelleri is restricted to shallow lake margins ( $<4 \mathrm{~m}$ depth) in both systems. Lake Macquarie has maintained stable and slightly increasing seagrass populations over the last few decades, with seagrass coverage of $13.4,14.7$, and $15.3 \mathrm{~km}^{2}$ surveyed in
1981, 1997, and 2009, respectively (Creese et al. 2009). Due to its shallow mean depth, Tuggerah Lakes historically had high levels of seagrass coverage: up to $42 \%$ of the lake area covered by seagrass between 1963 and 1966 (King \& Hodgson 1995). By 1985 , this coverage had fallen to $19.1 \mathrm{~km}^{2}$, or $22 \%$ of the lake, and the latest survey in 2009 showed coverage at $17.3 \mathrm{~km}^{2}$ (King \& Hodgson 1995, Creese et al. 2009). These declines are documented to have occurred at the seagrass lower depth limit (King \& Hodgson 1995).

\section{Water quality}

Water quality was monitored monthly at 3 and 6 locations in Tuggerah Lakes and Lake Macquarie, respectively, between April 2009 and April 2014 (Fig. 1). These sites were chosen to represent the primary water-quality gradients within the lakes based on an analysis of spatially intensive water quality data taken over the previous 2 yr (A. J. P. Ferguson unpubl. data). In Tuggerah Lakes, there is commonly a decoupling between nearshore (0-500 m offshore) and lake basin water quality due to the sheltering effects of nearshore macrophytes on mixing. This was not observed in Lake Macquarie. Accordingly, water-quality measurements in Tuggerah Lakes included an additional set of nearshore water quality
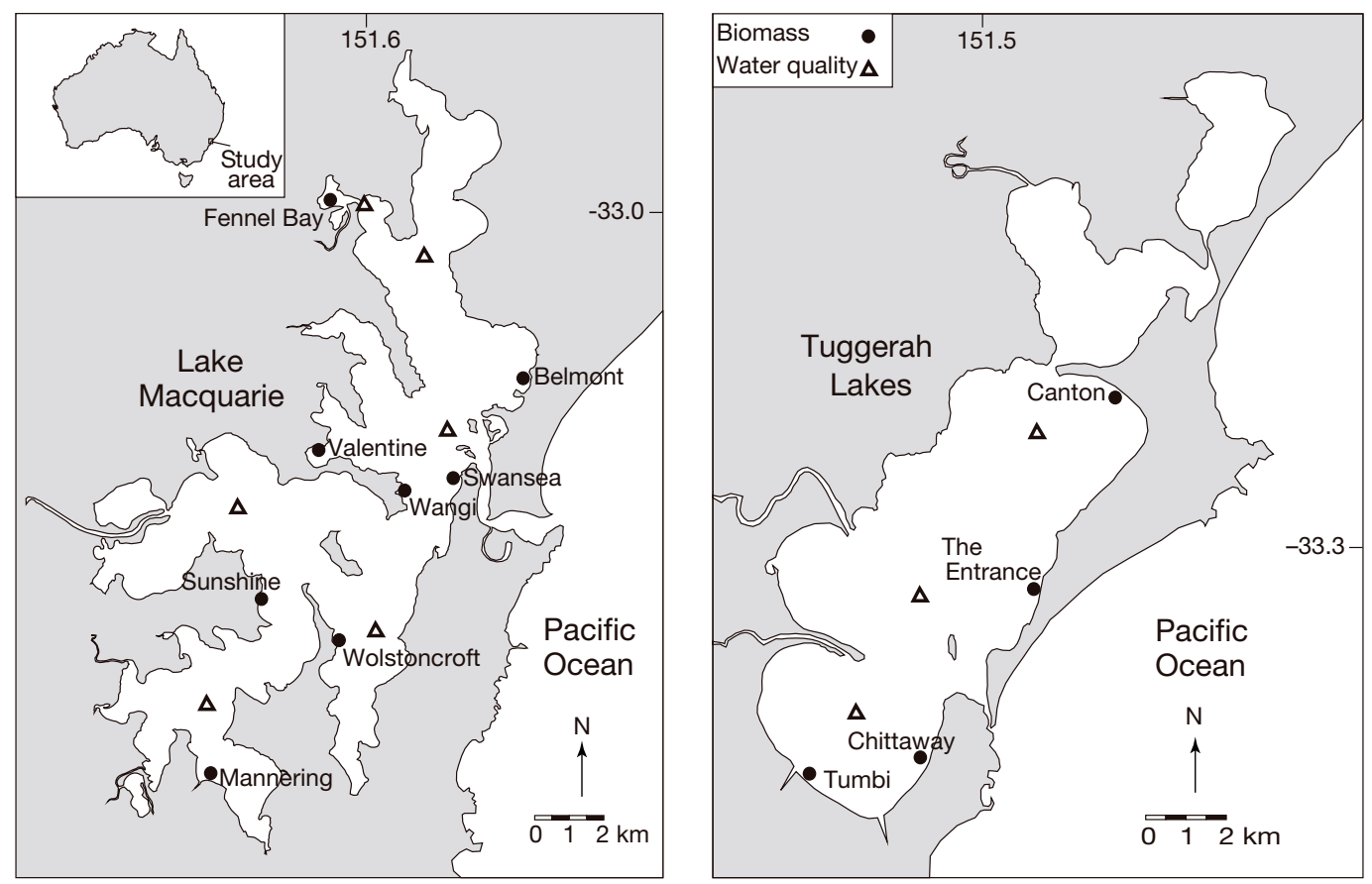

Fig. 1. Study area showing locations of seagrass biomass and water quality sampling sites 
sites at each of the shallow seagrass biomass sites. At each site, physico-chemical profiles (temperature, conductivity, dissolved oxygen, turbidity) were taken using a datalogging sonde (Yellow Springs Instruments Model 6920V2). Triplicate integrated samples of the upper $1 \mathrm{~m}$ of the water column were collected for nutrient and chlorophyll a (chl a) analysis. Samples for nutrient (total nitrogen and phosphorus) analysis were placed in sample-rinsed polyethylene vials and frozen immediately until analysis ( $\leq 1 \mathrm{mo}$ ). Chl a samples were placed in the dark, filtered (Whatman GF/F $0.7 \mu \mathrm{m}$ ) upon return to the laboratory, and filters were then frozen until analysis $(\leq 1$ mo) by extraction and fluorometry (Strickland \& Parsons 1968). All nutrient analyses were carried out colourimetrically using automated flow-injection (LACHAT Quick Chem 8000). Analytical accuracy for nutrient analysis was maintained using standard additions of certified laboratory standards in both Milli-Q and low-nutrient seawater.

\section{Light climate estimation}

Photosynthetic active radiation $\left(\mathrm{PAR}_{\mathrm{i}} \mathrm{mol} \mathrm{m} \mathrm{m}^{-2} \mathrm{~d}^{-1}\right)$ was estimated from solar exposure data (MJ $\mathrm{d}^{-1}$; source: Australian Bureau of Meterology) using the equation:

$$
\mathrm{PAR}=\text { solar exposure } \times 0.42 / 217.316 \times 1000
$$

assuming that the visible fraction (400-700 $\mathrm{nm}$ band) is $42 \%$ of total solar energy (Sokolik 2008). The factor 217.316 represents the molar ratio of photons to energy for $550 \mathrm{~nm}$, being the mid-point of the visible band. The light climate at the seagrass canopy of each site for the years preceding and during sampling was estimated using estimated PAR, depth, and a light attenuation coefficient $\left(K_{\mathrm{d}}\right)$ from the following equation:

Light climate $\left(\right.$ site $_{i}$ depth $\left._{i}\right)=$ incident PAR $(2$ year mean $) \times \exp \left(K_{\mathrm{d} i} \times\right.$ depth $\left._{i}\right)$

where depth ${ }_{i}$ was the mean depth at the top of the seagrass canopy at site ${ }_{i}$ and $K_{\mathrm{d}}$ was estimated from the median Secchi depth (based on 2 yr of monthly measurements) using the equation:

$$
K_{\mathrm{d}}=1.42 / \text { Secchi depth }
$$

Secchi depth data were taken from the nearest water-quality station for each site. In the case of Tuggerah Lakes, $K_{\mathrm{d}}$ for shallow sites was estimated based on turbidity measures made at nearshore stations using the equation:

$$
K_{\mathrm{d}}=0.15 \times \text { turbidity }
$$

$K_{\mathrm{d}}$ for the mid-Tuggerah Lakes sites was taken to be the mean of nearshore and lake basin $K_{\mathrm{d}}$, while $K_{\mathrm{d}}$ at the deep sites were estimated from the nearest lake basin site. The coefficients 1.42 and 0.15 were derived from the means of 25 parallel measurements of $K_{\mathrm{d}}$ (the attenuation rate of PAR within the water column), turbidity and Secchi depth in a range of nearby estuaries (A. J. P. Ferguson unpubl. data). Profiles of PAR were measured using a high-resolution profiling reflectance radiometer (Biospherical Instruments PRR 800) and a 2pi Licor underwater quantum sensor (LI-192).

\section{Seagrass biomass and morphometrics}

Monitoring of $Z$. muelleri populations was conducted at 4 sites in Tuggerah Lakes, and 8 sites in Lake Macquarie (Fig. 1), which were sampled seasonally during 2010-2012. Sites were chosen to represent a broad range of environmental conditions present in each lake, with consideration made for depth limit of seagrass occurrence, direction of significant fetch, sediment type, proximity to rivers, and proximity to the lake entrance. Within each site, 3 sub-sites ('shallow', 'middle', and 'deep') were selected based on depth extent of seagrass colonistion. Shallow subsites were 10-20 m offshore from the shallowest occurrence of seagrass (typically the shoreline), while deep sub-sites were 10-20 m shoreward of the deepest occurrence of seagrass. Middle sub-sites were evenly spaced between these extremes. Therefore, sub-sites were variable in depth and distance from neighbouring sub-sites, but were similar in representing the thresholds of seagrass tolerance across depth gradients. Absolute depths at each sub-site were estimated based on direct measures using a sounding line corrected to mean lake level.

Samples were collected in early spring, late spring, mid-summer, and late autumn. Three haphazard seagrass samples were collected by divers from within a circular sampling quadrat $(15.5 \mathrm{~cm}$ diameter). All biomass was removed from within the quadrat; below-ground material was sampled by cutting along the ring perimeter and removing material to $\sim 20 \mathrm{~cm}$ depth. All biomass was placed in a fine mesh bag while underwater; at the surface, samples were rinsed to remove sediment from below-ground material and placed in plastic bags. Upon return to the laboratory, seagrass samples were refrigerated $\left(4^{\circ} \mathrm{C}\right)$ until processing (2-5 d later). 
Thawed samples were rinsed in freshwater to remove salt, fauna, and residual sediment. Epiphytic algae were removed with gentle scraping. Material was then separated into above- and below-ground categories, and dead biomass (detached and blackened) was removed. The number of shoots present in each sample was counted to determine shoot density. Five random shoots were then chosen for measurement of length and width of the second-oldest leaf. The second-oldest leaf was used for standardisation as it accurately represented canopy height but was less likely to be broken or damaged than the oldest leaf. AGB and BGB were oven-dried $\left(60^{\circ} \mathrm{C}\right)$ for $3-5 \mathrm{~d}$ and then weighed. Leaf area index (LAI) was estimated as:

$$
\text { LAI = leaf surface area } / \text { shoot } \times \text { shoot density }
$$

\section{Sediment properties}

Sediment properties (grain size and OM content) were measured at each seagrass site over the depth gradient. Sediment sampling was conducted once during spring 2010, as it was assumed sediment properties would not change radically over the study period. At each sub-site, 6 samples of the uppermost $1 \mathrm{~cm}$ of sediment were collected haphazardly using a Perspex cylinder $(7 \mathrm{~cm}$ diameter). Samples were stored refrigerated $\left(4^{\circ} \mathrm{C}\right)$ until processing $(\leq 2 \mathrm{wk}$ later). Triplicate samples were used to determine $\mathrm{OM}$ content through loss on ignition $\left(550^{\circ} \mathrm{C}\right.$ for $\left.4 \mathrm{~h}\right)$. Sediment grain size was determined using dry and wet sieving. Wet sieving was used to separate the silt/clay fraction (<63 um grain size), and the remaining material was oven-dried $\left(60^{\circ} \mathrm{C}\right)$ and sieved to measure sand (63-2000 $\mu \mathrm{m})$ and gravel fractions (>2000 $\mu \mathrm{m})$.

\section{Statistical analysis}

Water-quality data were pooled according to lake, and differences between lakes were tested by ANOVA. Differences among depths and lakes for sediment properties, seagrass biomass, and morphometrics were tested using a 2-way ANOVA. Heterogeneity of variances and normality of data were tested and data were transformed where necessary. If differences between depths were found, Bonferroni and Tamhane post hoc tests (SPSS v.10) were used to identify which means differed. Relationships between light, sediment properties, seagrass biomass, and morphometrics were assessed using principal components analysis (SPSS v.10) with Varimax rotation, and scores from the first 3 components were classified by $k$-means cluster analysis (SPSS v.10). Differences in cluster attributes were tested by ANOVA.

\section{RESULTS}

\section{Water quality}

A larger catchment area to lake volume ratio meant that Tuggerah Lakes freshened more than Lake Macquarie in response to runoff events, with salinity typically remaining depressed throughout winter (Table 1A). In contrast, salinity in Lake Macquarie recovered to near seawater levels rapidly due to the relatively smaller freshwater inputs and more efficient oceanic exchange. Concentrations of total nitrogen were significantly greater in Tuggerah Lakes $(\mathrm{p}<$ 0.0001), whereas there was no significant difference between the lakes for total phosphorus. As such, the total nitrogen to total phosphorus ratios were consistently higher in Tuggerah Lakes, especially during

Table 1. Water-quality statistics (means $\pm \mathrm{SD}$ ) for $(\mathrm{A})$ Lake Macquarie and Tuggerah Lakes basin sites and (B) nearshore sites within Tuggerah Lakes (sites were as for seagrass biomass; see Fig. 1). TN: total nitrogen; TP: total phosphorus; DO: dissolved oxygen; ns: not significant

\begin{tabular}{|c|c|c|c|c|c|}
\hline (A) & \multicolumn{2}{|c|}{ Lake Macquarie } & \multicolumn{2}{|c|}{ Tuggerah Lakes } & $\mathrm{p}$ \\
\hline Salinity (PSU) & \multicolumn{2}{|c|}{$32.26 \pm 3.70$} & \multicolumn{2}{|c|}{$28.31 \pm 4.97$} & $<0.001$ \\
\hline $\mathrm{TN}\left(\mu g \mathrm{l}^{-1}\right)$ & \multicolumn{2}{|c|}{$193.45 \pm 72.8$} & \multicolumn{2}{|c|}{$341.18 \pm 67.1$} & $<0.001$ \\
\hline $\mathrm{TP}\left(\mu \mathrm{g} \mathrm{l}^{-1}\right)$ & \multicolumn{2}{|c|}{$19.95 \pm 8.22$} & \multicolumn{2}{|c|}{$16.90 \pm 8.40$} & ns \\
\hline TN:TP & \multicolumn{2}{|c|}{$22.01 \pm 4.08$} & \multicolumn{2}{|c|}{$50.46 \pm 15.5$} & $<0.001$ \\
\hline Chl a $\left(\mu g \mathrm{l}^{-1}\right)$ & \multicolumn{2}{|c|}{$2.11 \pm 1.45$} & & $1.01 \pm 2.02$ & $<0.001$ \\
\hline Turbidity (NTU) & \multicolumn{2}{|c|}{$2.24 \pm 2.63$} & & $5.03 \pm 4.63$ & $<0.001$ \\
\hline Secchi depth (m) & \multicolumn{2}{|c|}{$3.52 \pm 1.61$} & & $1.57 \pm 0.59$ & $<0.001$ \\
\hline (B) & Tumbi & Chitt & away & The Entrance & Canton \\
\hline Salinity (PSU) & $25.7 \pm 3.8$ & 24.6 & \pm 3.6 & $25.4 \pm 4.3$ & $23.8 \pm 4.3$ \\
\hline $\mathrm{TN}\left(\mu g \mathrm{l}^{-1}\right)$ & $511.7 \pm 128$ & 779.9 & \pm 399 & $388.5 \pm 61$ & $548.7 \pm 96.3$ \\
\hline $\operatorname{TP}\left(\mu g \mathrm{l}^{-1}\right)$ & $32.6 \pm 12.8$ & 45.9 & \pm 45.4 & $18.7 \pm 6.7$ & $28.7 \pm 14.2$ \\
\hline TN:TP & $34.8 \pm 22.2$ & 37.6 & \pm 19.5 & $46.1 \pm 20.3$ & $42.4 \pm 15.0$ \\
\hline Chl $a\left(\mu g l^{-1}\right)$ & $3.4 \pm 2.7$ & 4.5 & \pm 4.6 & $2.4 \pm 1.4$ & $3.1 \pm 1.8$ \\
\hline Turbidity (NTU) & $12.7 \pm 5.0$ & 7.3 & \pm 10.7 & $2.7 \pm 1.7$ & $4.2 \pm 3.6$ \\
\hline DO (\% saturation) & $92.6 \pm 17.4$ & 91.7 & \pm 35.8 & $102.9 \pm 28.3$ & $89.2 \pm 16.8$ \\
\hline
\end{tabular}


winter and spring. A prominent feature of Tuggerah Lakes was organic and nutrient enrichment of the nearshore zone (within $100 \mathrm{~m}$ of the shoreline) due to the trapping of localised stormwater and groundwater inputs by macroalgae and seagrass growth (King \& Hodgson 1995). This was reflected by the lower salinities and higher nutrient concentrations at the nearshore Tuggerah Lakes sites (Table 1B). Chl a concentrations were significantly higher in Tuggerah Lakes, further confirming greater nutrient enrichment relative to Lake Macquarie. As a result of reduced turbidity and chl a levels, light penetration (as indicated by Secchi depths) was significantly greater in Lake Macquarie (mean $K_{\mathrm{d}}=0.43 \mathrm{~m}^{-1}$ ) than Tuggerah Lakes (mean $K_{\mathrm{d}}=0.82 \mathrm{~m}^{-1}$ ).

\section{Sediment quality}

The fine sediment (silt/clay) fraction was significantly greater in Tuggerah Lakes, with no significant differences among depths in either lake (Fig. 2, Table 2). There was no overall significant difference in OM content between the 2 lakes.

\section{Seagrass biomass and morphometrics}

AGB was significantly greater in Tuggerah Lakes compared with Lake Macquarie (Fig. 3, Table 2). Tuggerah Lakes showed differences along the depth gradient, with shallow and middle-depth sites having significantly greater AGB than deep sites (Fig. 3A). BGB was significantly greater in Lake Macquarie (Fig. 3B). There was a significant interaction between lake and depth for $B G B$, with a significant reduction in BGB along the depth gradient in Lake Macquarie. This pattern was strongly related $\left(\mathrm{r}^{2}=0.68\right)$ to light level (Table 3). The seagrass communities of Tuggerah Lakes displayed no differences in BGB among depths.

Shoot density was significantly greater in Lake Macquarie than Tuggerah Lakes, and a reduction in density with depth was observed in both lakes (Table 2, Fig. 3E). In contrast, shoot length was much greater in Tuggerah Lakes, with a significant increase in length with depth in Lake Macquarie only (Fig. 3F). There was a significant increase in leaf
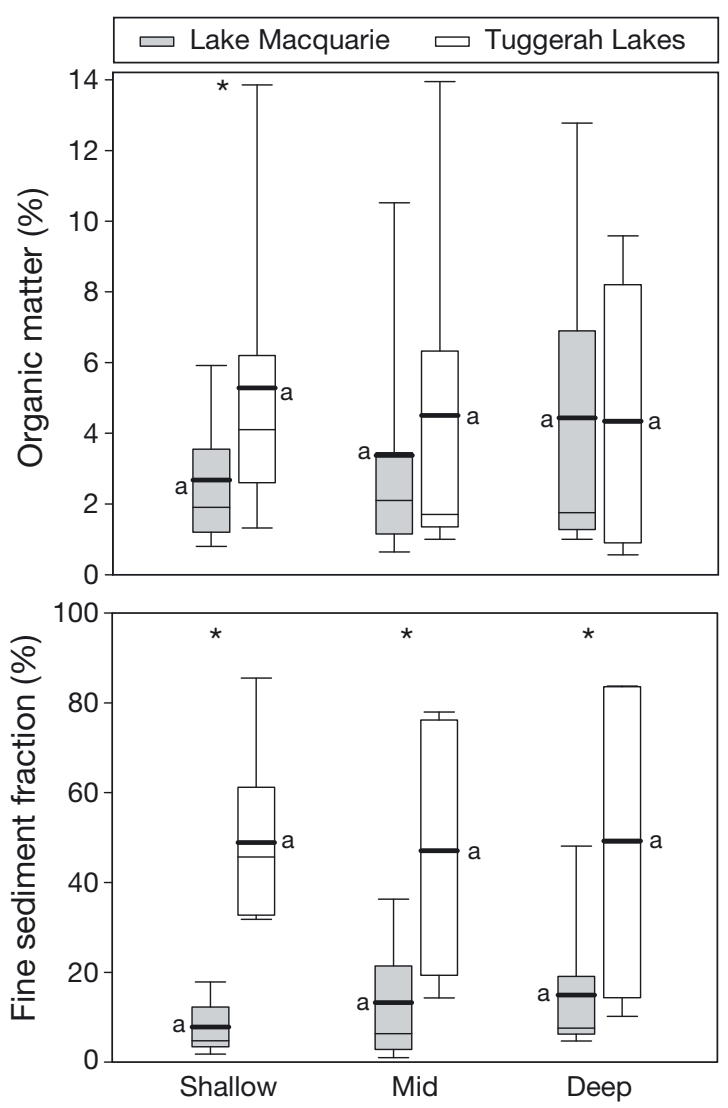

Fig. 2. Mean percent organic matter content and fine sediment $(<63 \mu \mathrm{m})$ fraction at seagrass sampling sites in Lake Macquarie and Tuggerah Lakes. Lowercase letters indicate significant differences among depths within each lake. Asterisk at the top of the plot indicates a significant difference between lakes within each depth. The lower and upper boundaries of the boxes equal the 25th and 75th percentiles, respectively, the narrow and thick lines within the box equal the median and mean, respectively, and the lower and upper whiskers equal the 10th and 90th percentiles, respectively 

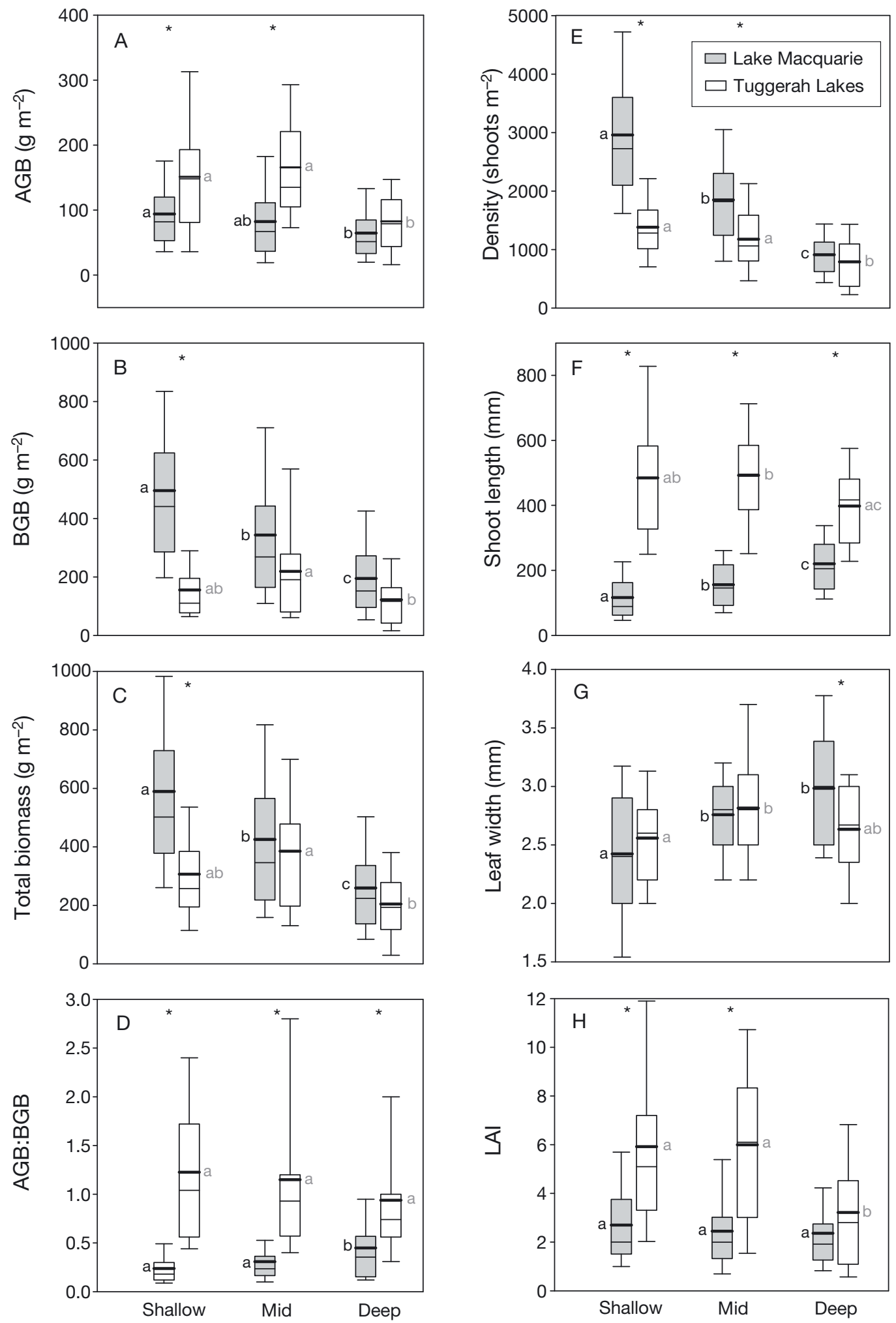

Fig. 3. Seagrass biomass and morphology across the depth gradient in Lake Macquarie and Tuggerah Lakes: (A) aboveground biomass (AGB); (B) below-ground biomass (BGB); (C) total biomass (TB); (D) AGB:BGB ratio; (E) shoot density; (F) shoot length; $(\mathrm{G})$ leaf width; and $(\mathrm{H})$ leaf area index (LAI). Lowercase letters indicate significant differences among depths within each lake. Asterisk at the top of the plot indicates a significant difference between lakes within each depth. See Fig. 2 
Table 3. Inter-correlations (Pearson's correlation coefficient r) for seagrass biomass, morphometrics and environmental stressors. Bold values are significant at $\mathrm{p}<0.05$, and bold values with an asterisk are significant at $\mathrm{p}<0.01$. See Table 2 for abbreviations

\begin{tabular}{|c|c|c|c|c|c|c|c|c|c|c|c|}
\hline & AGB & BGB & TB & Density & AGB:BGB & Length & LAI & Fines & Sand & OM & Light \\
\hline $\mathrm{AGB}$ & 1.00 & & & & & & & & & & \\
\hline BGB & 0.12 & 1.00 & & & & & & & & & \\
\hline TB & 0.36 & $0.97^{*}$ & 1.00 & & & & & & & & \\
\hline Density & -0.09 & $0.71^{*}$ & $0.64^{*}$ & 1.00 & & & & & & & \\
\hline AGB:BGB & $0.64^{*}$ & $-0.56^{*}$ & -0.37 & $-0.44^{*}$ & 1.00 & & & & & & \\
\hline Length & $0.55^{*}$ & $-0.56^{*}$ & -0.39 & $-0.59^{*}$ & $0.76^{*}$ & 1.00 & & & & & \\
\hline LAI & $0.80^{*}$ & -0.14 & 0.06 & -0.12 & $0.68^{*}$ & $0.75^{*}$ & 1.00 & & & & \\
\hline Fines & 0.19 & $-0.60^{*}$ & $-0.52^{*}$ & -0.43 & $0.63^{*}$ & $0.71^{*}$ & $0.47^{*}$ & 1.00 & & & \\
\hline Sand & -0.08 & 0.28 & 0.24 & 0.00 & -0.36 & -0.42 & -0.35 & $-0.83^{*}$ & 1.00 & & \\
\hline OM & 0.03 & -0.33 & -0.31 & -0.24 & 0.25 & 0.31 & 0.21 & $0.69^{*}$ & $-0.67^{*}$ & 1.00 & \\
\hline Light & 0.04 & $0.75^{*}$ & $0.72^{*}$ & $0.77^{*}$ & $-0.46^{*}$ & $-0.55^{*}$ & -0.09 & -0.41 & 0.11 & -0.16 & 1.00 \\
\hline
\end{tabular}

width with depth, but no differences between lakes (Fig. 3G). There were no trends in the number of leaves per shoot (data not shown). LAI was significantly greater in Tuggerah Lakes, and there were no
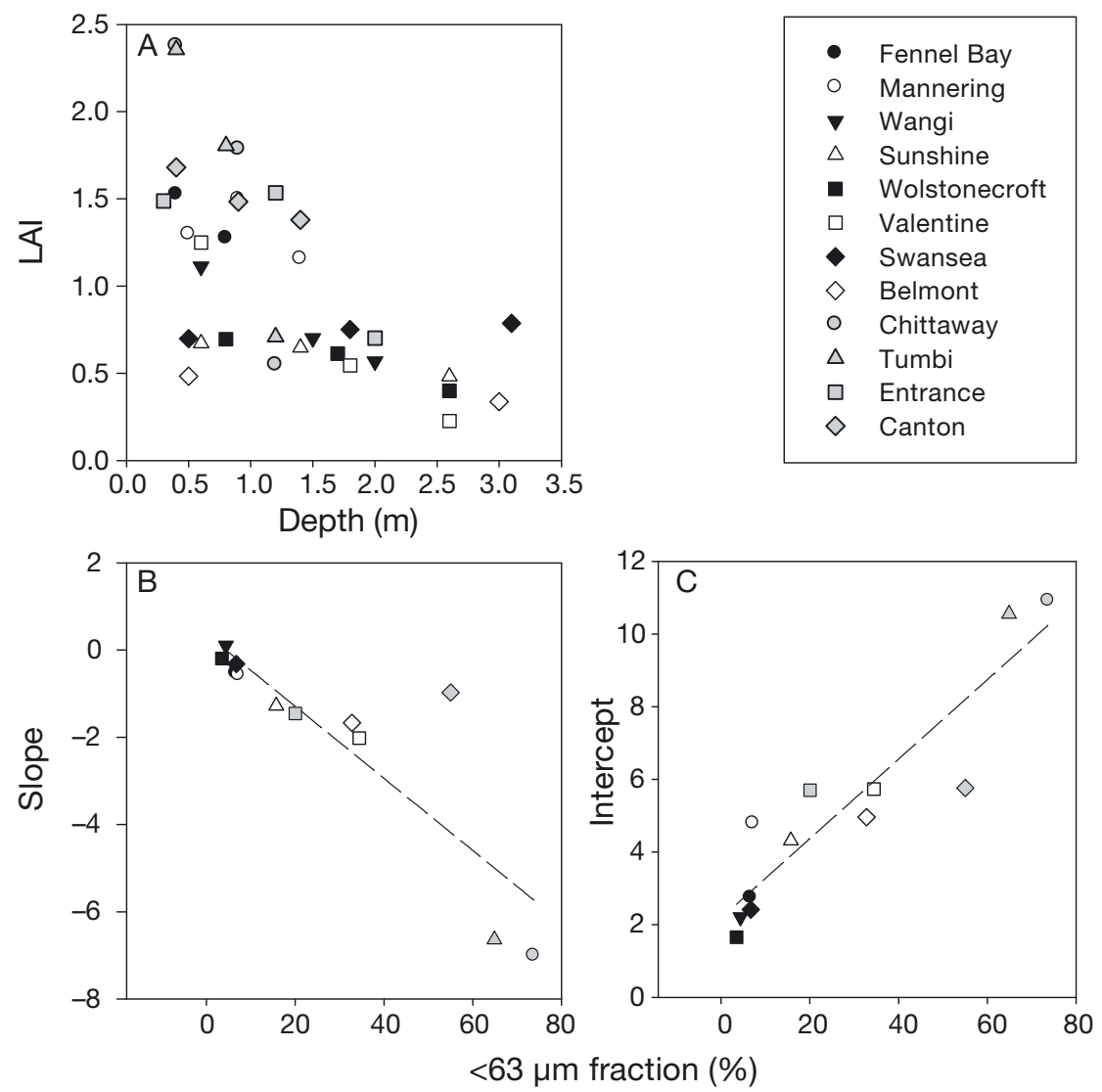

Fig. 4. Relationships between (A) sample depth and leaf area index (LAI) (depth means for each site); (B) fine sediment fraction and the slope of depthdependent relationships for LAI; and (C) fine sediment fraction $(<63 \mu \mathrm{m})$ and the intercept of depth-dependent relationships for LAI. See Fig. 1 for site locations depth-related trends in LAI at the lake level (Fig. 3H). There were, however, site-specific depthdependent trends in LAI, which varied as a function of the fine sediment fraction: LAI was highest, and the decrease in LAI with depth was greatest in association with high fine sediment fractions (Fig. 4).

The mean $( \pm \mathrm{SD})$ ratio of $\mathrm{AGB}$ to BGB was significantly higher in Tuggerah Lakes $(1.15 \pm 0.81)$ compared to Lake Macquarie (0.31 \pm 0.29$)$ (Fig. 3D). There was a significant interaction between lake and depth for AGB:BGB, with significantly higher ratios at deep sites in Lake Macquarie and no significant differences among depths in Tuggerah Lakes (Fig. 3C). There was a tight coupling between AGB and BGB in Tuggerah Lakes $\left(y=0.79 x ; r^{2}=0.72\right)$, with a much poorer relationship observed for Lake Macquarie ( $y=$ $\left.0.18 x ; r^{2}=0.07\right)$. Shoot length was positively correlated with AGB:BGB in both lakes $\left(\mathrm{r}^{2}=0.76\right.$; Table 3$)$. Interestingly, there were opposing relationships between light and AGB:BGB in the 2 lakes, with AGB:BGB negatively related to light in Lake Macquarie and positively related to light in Tuggerah Lakes. There was a decrease in BGB with increasing fine sediment fraction observed across the 2 lakes (Table 3), which drove a strong relationship between AGB:BGB and fine sedi- 

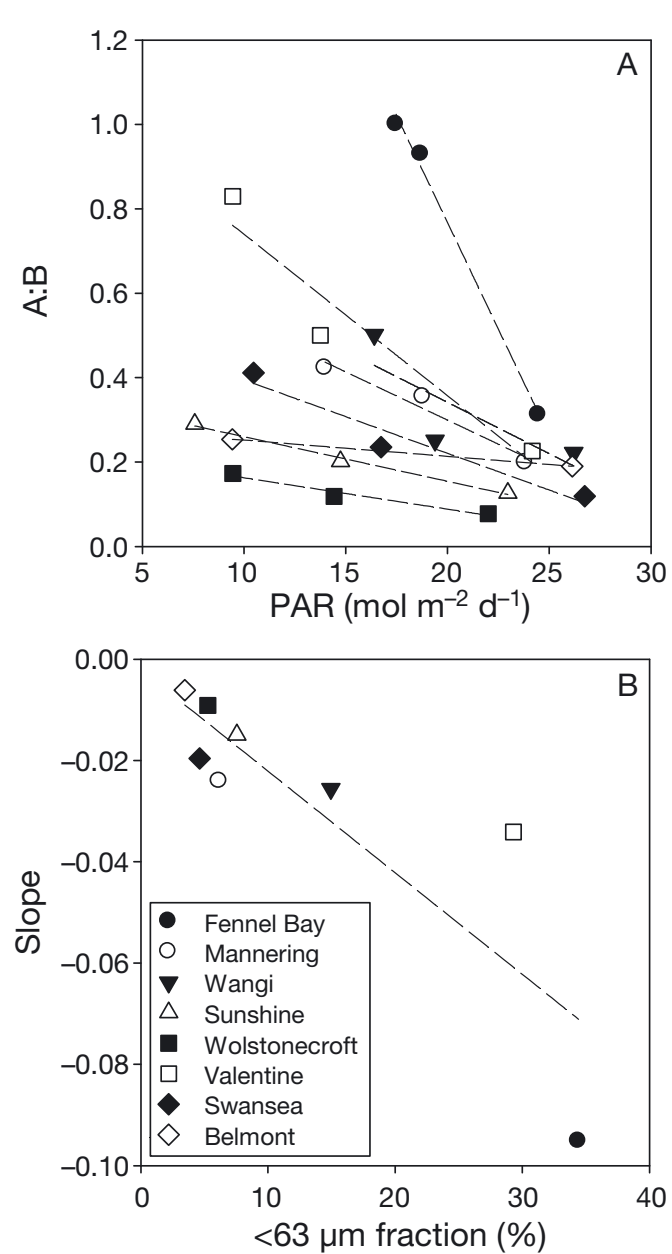

Fig. 5. (A) Site-specific relationships between light and the AGB:BGB ratio (depth means for each site) in Lake Macquarie (note: sites are as shown in Fig. 1). (B) The different slopes of the relationships are controlled by the fine sediment fraction and nutrient status: the lowest slope was at the most oligotrophic site, while the highest slope was at the enriched Fennel Bay site. See Fig. 1 for site locations

ment fraction (Table 3). Considering the Lake Macquarie sites in isolation revealed site-specific slopes in the relationship between light and AGB:BGB (Fig. 5A), with the different regression slopes explained by variation in the fine sediment fraction between sites (Fig. 5B).

\section{Factor analysis}

A PCA loading plot was used to examine the relationships between light, sediment properties, seagrass biomass, and morphometrics (Fig. 6). Three components accounted for $86 \%$ of the variance: the first (48\%) was strongly associated with positive relationships among light, BGB, and shoot density; the

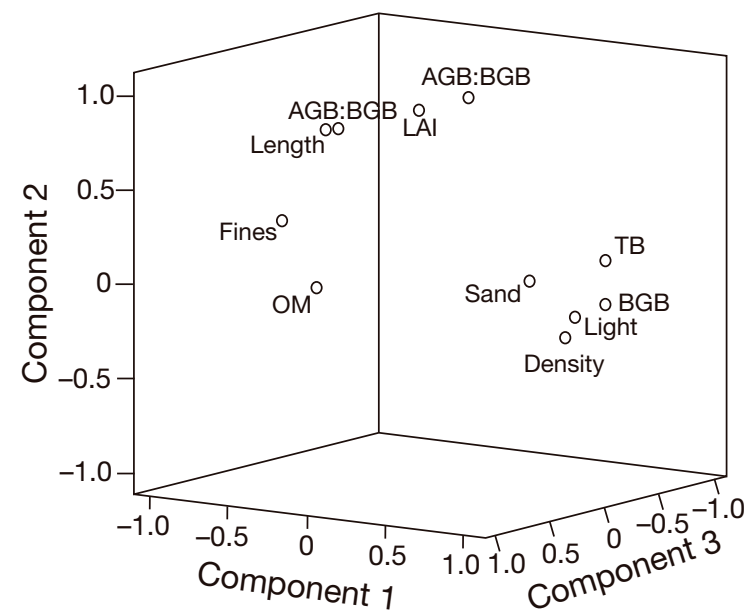

Fig. 6. Principle components loading plot of seagrass biomass, morphometrics and environmental drivers. AGB: above-ground biomass; BGB: below-ground biomass; TB: total biomass (AGB+BGB); length: shoot length; density: shoot density; LAI: leaf area index; light: annual mean light at each depth; fines: fine sediment fraction $(<63 \mu \mathrm{m})$; sand: sand sediment fraction $(63-1000 \mu \mathrm{m}) ; \mathrm{OM}$ : organic matter content

Table 4. Number of cases (samples) in each cluster yielded from a $k$-means cluster analysis of principle components analysis scores

\begin{tabular}{|lcrrr|}
\hline & & \multicolumn{3}{c|}{ Cluster } \\
& & 1 & 2 & \multicolumn{1}{c|}{3} \\
\hline \multirow{2}{*}{ Depth } & Shallow & 6 & 38 & 58 \\
& Mid & 40 & 35 & 22 \\
& Deep & 83 & 6 & 0 \\
& Lake & 92 & 4 & 78 \\
& Tuggerah Lakes & 37 & 75 & 2 \\
& & & & \\
\hline
\end{tabular}

second (23\%) was associated with positive relationships among AGB, AGB:BGB, shoot length, and LAI; and the third (15\%) was associated with sediment fine fraction, sand fraction, and OM content. Cluster analysis of factor scores yielded 3 clusters. Cluster membership for depth and lake indicate that Cluster 1 represents deep sites within both lakes, Cluster 2 represents the shallow and intermediate sites in Tuggerah Lakes, and Cluster 3 represents shallow and intermediate sites in Lake Macquarie (Table 4). The fine sediment fraction, sediment OM content, seagrass biomass, and morphometric properties were significantly different among clusters (Table 5).

\section{Depth ranges}

There was a reasonably strong relationship between mean annual Secchi depth and seagrass depth range 
Table 5. Attributes of each cluster yielded from a $k$-means cluster analysis of principle components analysis scores. Values with the same superscript letters indicate no significant difference among clusters for each attribute. See Fig. 6 for abbreviations

\begin{tabular}{|lccc|}
\hline \multicolumn{3}{c|}{ Cluster } \\
& 1 & 2 & 3 \\
\hline AGB & $58 \pm 7^{\mathrm{a}}$ & $114 \pm 11^{\mathrm{b}}$ & $103 \pm 12^{\mathrm{c}}$ \\
BGB & $157 \pm 20^{\mathrm{a}}$ & $85 \pm 10^{\mathrm{a}}$ & $475 \pm 34^{\mathrm{b}}$ \\
TB & $215 \pm 24^{\mathrm{a}}$ & $199 \pm 17^{\mathrm{a}}$ & $578 \pm 41^{\mathrm{b}}$ \\
AGB:BGB & $0.5 \pm 0.07^{\mathrm{a}}$ & $1.6 \pm 0.19^{\mathrm{b}}$ & $0.2 \pm 0.03^{\mathrm{c}}$ \\
Density & $1002 \pm 101^{\mathrm{a}}$ & $1163 \pm 92^{\mathrm{a}}$ & $2897 \pm 171^{\mathrm{b}}$ \\
Length & $236 \pm 22^{\mathrm{a}}$ & $372 \pm 30^{\mathrm{b}}$ & $105 \pm 11^{\mathrm{c}}$ \\
LAI & $4.1 \pm 0.6^{\mathrm{a}}$ & $7.4 \pm 0.9^{\mathrm{b}}$ & $4.9 \pm 0.6^{\mathrm{a}}$ \\
Fines & $22.7 \pm 4^{\mathrm{a}}$ & $49.5 \pm 5^{\mathrm{b}}$ & $8.4 \pm 1^{\mathrm{c}}$ \\
OM & $3.8 \pm 0.6^{\mathrm{ab}}$ & $4.9 \pm 0.8^{\mathrm{b}}$ & $2.7 \pm 0.3^{\mathrm{a}}$ \\
Light & $271 \pm 50^{\mathrm{a}}$ & $413 \pm 30^{\mathrm{b}}$ & $522 \pm 35^{\mathrm{c}}$ \\
\hline
\end{tabular}

Table 6. Results of multiple regression analysis for predictors of seagrass depth ranges. Secchi depth is the annual mean for each site. OM: organic matter; fines: fine sediment fraction

\begin{tabular}{|lrrc|}
\hline & \multicolumn{1}{c}{$\beta$} & \multicolumn{1}{c|}{$t$} & $\mathrm{p}$ \\
\hline Secchi & 0.65 & 3.11 & 0.01 \\
OM & -0.44 & -2.89 & 0.02 \\
Fines & 0.01 & 0.06 & 0.95 \\
\hline
\end{tabular}

$\left(r^{2}=0.66, p=0.001\right.$; Fig. 7A). However, there was considerable variation in the estimated light climate at the depth limit across the sites, with generally deeper limits for a given light climate in Lake Macquarie. Multiple linear regression analysis indicated that inclusion of Secchi depth, fine sediment fraction, and OM content greatly improved the prediction of depth limits $\left(\mathrm{r}^{2}=0.92, \mathrm{p}=0.0001\right.$; Table 6,
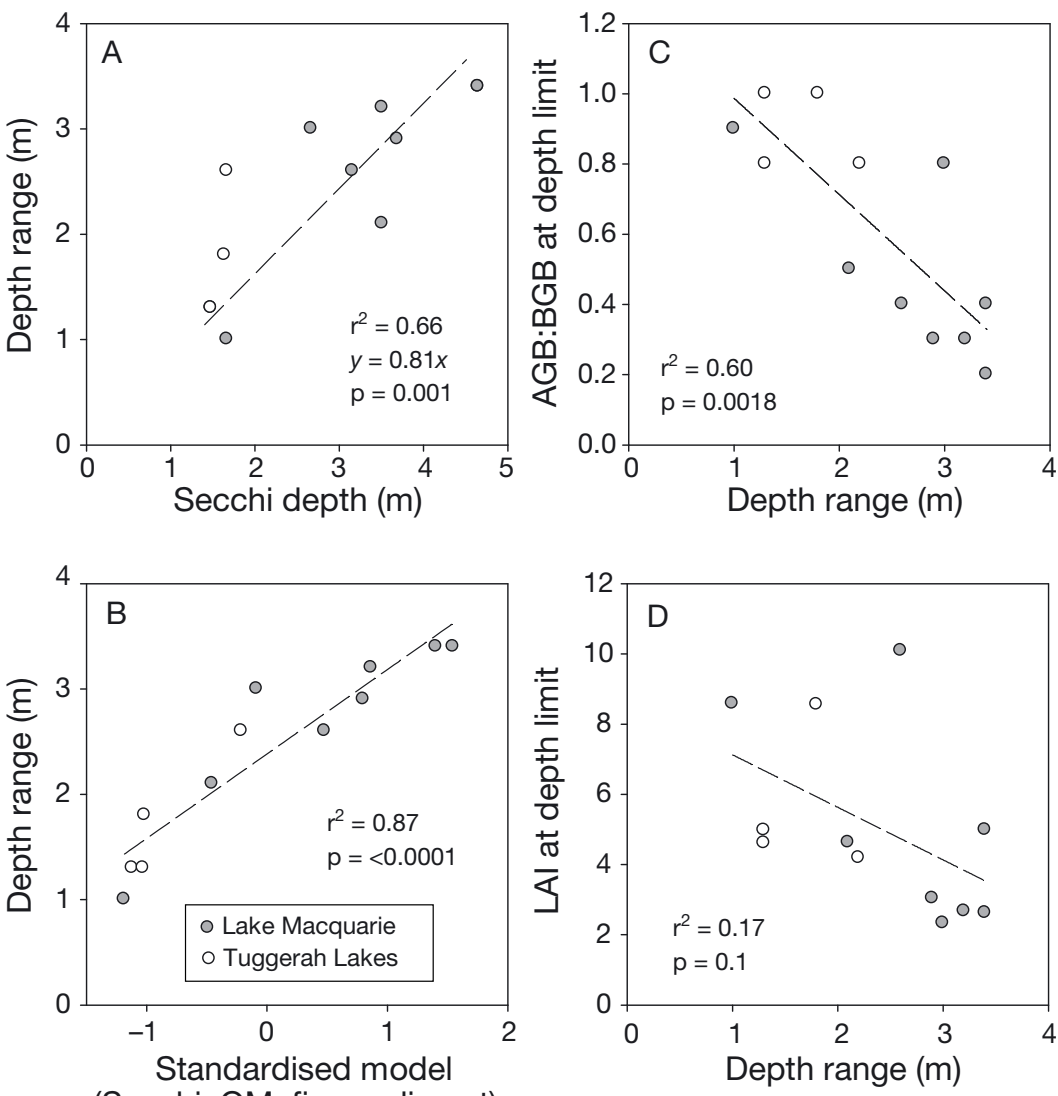

(Secchi, OM, fine sediment)

Fig. 7. Relationships between (A) mean annual Secchi depth and depth range at the study sites in both lakes; (B) the predicted standardised value from the multilinear regression model, including Secchi depth, fine sediment fraction and OM (see Table 5 for regression results), and depth range; $(C)$ depth range and the mean annual AGB:BGB value at the depth limit (annual mean); and (D) depth range and LAI at the depth limit (annual mean). See Fig. 6 for abbreviations
Fig. 7B). There was a significant reduction in AGB:BGB with increasing depth range $\left(\mathrm{r}^{2}=0.60, \mathrm{p}=0.0018\right.$; Fig. 7C). There was also a reduction in LAI with increasing depth range; however, this relationship was not significant (Fig. 7D).

\section{DISCUSSION}

The present study provided an opportunity to observe variation in biomass and morphometrics of Zostera muelleri populations occurring across a wide range of light, sediment quality, and nutrient conditions. Significant differences among depths indicated that light gradients were the primary control over total biomass, BGB, and shoot density across the study area (Fig. 3, Table 3). Although no general trends between light and AGB were found in this study, lakeand site-specific relationships between light, AGB:BGB, and LAI were seen to vary along gradients in nutrient and sediment quality.

\section{Factors influencing morphology}

Variation in LAI is commonly held to be a mechanism for minimising 
self-shading and photo-damage (Enríquez \& PantojaReyes 2005), and is usually observed to decrease in response to decreases in light across the depth gradient (Collier et al. 2007). There were no consistent reductions in LAI with depth or light detected for our dataset as a whole (Table 3); however, within sites there were varying reductions in LAI with depth (Fig. $4 \mathrm{~A})$. Both the slope and intercept of these depthdependent relationships were closely related to the fine sediment fraction (Fig. 4B,C), indicating that light-dependent variation in LAI was significantly influenced by sediment conditions. As such, variation in LAI across the entire study area was more closely related to the fine sediment fraction (Table 3), and was significantly greater in the more nutrientenriched areas of Tuggerah Lakes (Table 5). These trends suggest 2 main drivers: (1) the upregulation of areal $\mathrm{O}_{2}$ production and pumping to the rhizosphere in order to minimise sulphide exposure (Holmer \& Nielsen 1997); and (2) luxury growth of AGB in the presence of higher nutrient availability. This latter mechanism is supported by various experimental studies, which have shown an increase in AGB in response to fertilisation (Lee \& Dunton 2000b) and greater sediment OM content (Wicks et al. 2009).

The strong relationship between light and BGB (Table 3) suggests a morphological response to 2 opposing environmental forcing factors across the depth gradient: (1) nutrient limitation induced by higher potential rates of gross primary production in non-light-limited shallow environments (Cluster 3; Table 5); and (2) reductions in shoot density induced by light limitation and sulphide exposure approaching the depth limits (Cluster 1). In oligotrophic systems, seagrasses must satisfy a substantial portion of their nutrient requirements via the remineralisation of particulate nutrients in the rhizosphere and sediments (Gacia et al. 2002). In nutrient-limited environments this can cause a relative increase in BGB, which may reflect the dominance of nutrient uptake in the rhizosphere (Perez et al. 1994). A linkage between BGB and nutrient limitation also helps to explain the significantly higher BGB in the oligotrophic Lake Macquarie relative to the mesotrophic Tuggerah Lakes, although this result is also likely to be influenced by negative feedbacks associated with fine sediments (see below).

The negative relationship between sediment quality (OM content and fine sediment fraction) and BGB (Table 3) most likely indicates negative feedbacks associated with sulphide exposure (Fig. 7B). Exposure to sulphides in the rhizosphere is broadly controlled by: (1) the production of reduced sulphur resulting from sulphate reduction and (2) the supply of oxygen and/or oxides for re-oxidation of these reduced compounds. Sulphate reduction is stimulated by OM inputs in excess of the rate of aerobic respiration (Jørgensen 1982), and as such may be expected to increase with OM supply within the rhizosphere (Holmer et al. 2001). The re-oxidation of reduced sulphides is influenced by the rate of $\mathrm{O}_{2}$ pumping to the rhizosphere via roots (Lee \& Dunton 2000a), and also the rate of $\mathrm{O}_{2}$ diffusion within sediments, which is directly related to the fine sediment fraction. Our data suggest that this negative feedback on BGB may be significant once the fraction of sediments $<63 \mu \mathrm{m}$ exceeds $20 \%$. Working in concert with this mechanism is a need to minimise the respiratory costs of BGB to balance reduced gross primary production at depth (Hemminga 1998, Collier et al. 2007, 2008).

The AGB:BGB ratio is a useful morphological metric since it relates directly to the relative allocation of resources between photosynthetic organs with high respiratory demands and non-photosynthetic BGB with relatively low respiratory demands in response to environmental conditions (Fourqurean \& Zieman 1991). The AGB:BGB ratio integrates the plant response to all of the factors discussed above, and has more physiological meaning at the plant scale than stocks of biomass alone. The higher mean AGB:BGB ratios recorded for Tuggerah Lakes in the present study (0.6-1.2; Fig. 3) are in line with values for other northern hemisphere Zostera species (Duarte \& Chiscano 1999). AGB:BGB ratios in Lake Macquarie were well below this but generally in line with values reported for Z. capricorni in New Zealand harbours with similar sediment fine fraction contents (Matheson \& Schwarz 2007). Zostera meulleri in Tuggerah Lakes therefore represents a morph of Zostera that is similar to stands elsewhere in the world, whereas the Lake Macquarie morph (cluster 3; Table 5), along with the New Zealand Z. capricorni examples, represents a departure from the more widely studied variants. We suggest that the significant difference in AGB:BGB between lakes in the present study was primarily driven by the nutrient status and nutrient supply pathways of the 2 systems: higher AGB:BGB ratios in Tuggerah Lakes reflect higher nutrient availability in the water column and negative feedbacks associated with sediment quality, while low AGB:BGB ratios in Lake Macquarie reflect an oligotrophic pelagic environment with nutrient supply most likely dominated by the remineralisation of OM within the rhizosphere. 
The significant increase in AGB:BGB with decreases in light over depth gradients in Lake Macquarie is consistent with a previous experimental study (Abal et al. 1994) and observations for other species (Kraemer \& Mazzella 1996, Collier et al. 2007), fitting with the general theory that as light is reduced, seagrasses will invest more in photosynthetic organs (AGB) and reduce the relative liability of heterotrophic BGB in order to maintain a favourable carbon balance (Hemminga 1998). Although AGB:BGB in Lake Macquarie varied across depth gradients primarily due to light (Fig. 5A), the slope of this relationship was controlled by sediment quality (Fig. 5B). The increase in AGB with greater proportions of fine sediment could be explained by a need to offset the pressure associated with sulphide exposure (Holmer \& Nielsen 1997), suggesting that variation in AGB:BGB is linked to balancing the total community (i.e. plant + rhizosphere sediment) biogeochemical oxygen demands.

The highest AGB:BGB ratio was observed at the shallow and intermediate depths in Tuggerah Lakes (Cluster 2; Tables 4, 5). There were a number of interacting factors that most likely influenced this result. The Cluster 2 sites were found in low energy environments subject to high stormwater nutrient inputs, and this combination of positive pressures on AGB and negative pressures on BGB resulted in high AGB:BGB ratios. In addition, it is likely that reduced wave energy and bed shear stress allowed longer shoot development (Schanz \& Asmus 2003). Higher AGB:BGB ratios in association with fine sediment fraction was also observed in some cases in Raglan Harbour (Matheson \& Schwarz 2007) and experimentally (Wicks et al. 2009), and was consistent with our Cluster 2 sites (Table 5). However, there appear to be limits to this morphological response to sediment conditions; AGB:BGB rarely exceeded 2.5, even in sediments with very high fine and OM contents. The reasons for this were unclear, but may indicate a combination of physiological and morphological limitations to plasticity in $Z$. muelleri.

\section{Factors influencing seagrass depth range}

Our survey of morphological plasticity in response to environmental stressors described variation within the tolerable (i.e. sub-lethal) light range for $Z$. muelleri. In contrast, the depth limits of meadows provide an indication of thresholds in environmental conditions beyond which seagrass no longer survives. Seagrass depth range is a commonly employed measure of seagrass health, with variations in the lower limits of meadows primarily generally controlled by light attenuation (Dennison \& Alberte 1985, Dennison 1987b, Abal \& Dennison 1996, Greve \& Krause-Jensen 2005). The slope of the relationship between mean annual Secchi depth and depth range during our study (slope = 0.81; Fig. 7A) is consistent with a study of Zostera marina from a range of sites in Danish coastal waters (slope $=0.74$; (Krause-Jensen et al. 2011); however, there was still considerable unexplained variation in our data. Krause-Jensen et al. (2011) found that the residuals in the relationship between depth range and Secchi depth were partially explained by sediment properties (e.g. fine sediment fraction and sulphide concentrations). Similarly, we found that depth range was best explained by taking into account Secchi depth and the OM content of sediments (Table 6). This suggests that sulphide exposure associated with high OM and fine sediment contents increases the minimum light required by the plant in order to maintain a tolerable community oxygen balance. Interestingly, OM content had a stronger bearing on depth limits than fine sediments (Table 6), indicating that it is most likely the rate of sulphate reduction rather than sediment porosity that controls sulphide exposure at low light. This helps explain the wide scale loss of seagrass at its lower depth limit in Tuggerah Lakes that accompanied the enrichment of the lake basin with nutrients, OM and fine sediments during the 20th century.

A key question is the extent to which morphological plasticity (i.e. changes to LAI and AGB:BGB) helps moderate the negative impacts of sediment quality on the minimum light requirements of $Z$. muelleri. In the absence of limits to phenotypic plasticity, it would be expected that plants could acclimate such that varying sediment conditions would have no bearing on minimum light requirements (DeWitt et al. 1998). Our results clearly show that plant morphology responds to interactions between light and sediment quality gradients (e.g. Fig. 5); however, these responses are insufficient to completely compensate for the negative impacts of sediment quality on minimum light requirements (as indicated by Fig. 7B). It is notable that AGB:BGB did not exceed 1 at the depth limit (Fig. 7C), even at sites where higher values were recorded at shallower depths, suggesting a limit to morphology under lightlimited conditions. These limits may relate to selfshading impacts due to increases in LAI (Collier et al. 2007). 


\section{CONCLUSIONS}

Our results suggest that morphological plasticity may help Zostera muelleri acclimate across gradients of light, sediment quality, and nutrient enrichment in order to colonise a range of different environments within the estuarine ecological niche. While light gradients are primary regulators of seagrass biomass and morphology, these relationships are strongly dependent on sediment and nutrient gradients. Variations in LAI and AGB:BGB appear to be primary mechanisms facilitating acclimation to environmental conditions, and there is evidence that these variations occur not only to maintain favourable plant carbon balances, but also to minimise sulphide exposure in the rhizosphere. The largest variations in LAI and AGB:BGB occurred between the 2 lakes, hence variation in morphology across the study was dominated by interactions between nutrient status and sediment quality, thereby obscuring light-dependent trends in morphology at this scale. Sediment properties and nutrient status play key roles in modulating the minimum light requirements of $Z$. muelleri at its depth limit, supporting similar findings for other species (Krause-Jensen et al. 2011, Kenworthy et al. 2014) and highlighting the need to account for these environmental drivers in the interpretation of seagrass depth range data. Our results indicate that, while morphological plasticity may play a role in extending the range of this species, there are apparent limits to this plasticity at the lower depth limit. The description of limits to morphological plasticity of $Z$. muelleri in response to environmental stressor gradients (as summarised in Table 5) provides crucial information needed to parameterise biomass flux models for this species.

\section{LITERATURE CITED}

Abal EG, Dennison WC (1996) Seagrass depth range and water quality in southern Moreton Bay, Queensland, Australia. Mar Freshw Res 47:763-771

> Abal EG, Loneragan N, Bowen P, Perry CJ, Udy JW, Dennison WC (1994) Physiological and morphological responses of the seagrass Zostera capricorni Aschers, to light intensity. J Exp Mar Biol Ecol 178:113-129

Bulthuis DA (1983) Effects of in situ light reduction on density and growth of the seagrass Heterozostera tasmanica (Martens ex Aschers.) den Hartog in Western Port, Victoria, Australia. J Exp Mar Biol Ecol 67:91-103

Cayabyab NM, Enríquez S (2007) Leaf photoacclimatory responses of the tropical seagrass Thalassia testudinum under mesocosm conditions: a mechanistic scaling-up study. New Phytol 176:108-123

Cerco CF, Moore KA (2001) System-wide submerged aquatic vegetation model for Chesapeake Bay. Estuaries 24:522-534
Clores MA, Santos Carandang J (2013) Chlorophyll content, productivities and biomass allocations of seagrasses in Talim Bay, Lian, Batangas, Philippines. Proc Int Acad Ecol Environ Sci 3:247-256

Collier CJ, Lavery PS, Masini RJ, Ralph PJ (2007) Morphological, growth and meadow characteristics of the seagrass Posidonia sinuosa along a depth-related gradient of light availability. Mar Ecol Prog Ser 337:103-115

> Collier CJ, Lavery PS, Ralph PJ, Masini RJ (2008) Physiological characteristics of the seagrass Posidonia sinuosa along a depth-related gradient of light availability. Mar Ecol Prog Ser 353:65-79

Collier CJ, Lavery PS, Ralph PJ, Masini RJ (2009) Shadeinduced response and recovery of the seagrass Posidonia sinuosa. J Exp Mar Biol Ecol 370:89-103

Creese RG, Glasby TM, West G, Gallen C (2009) Mapping the habitats of NSW estuaries. In: Fisheries Final Report Series No 113. Report to HCRCMA Project No HCR 07_458 Department of Industry and Investment NSW, Sydney

Dennison WC (1987a) Effects of light distribution on seagrass photosythesis, growth, and depth distribution. Aquat Bot 27:15-26

Dennison WC (1987b) Effects of light on seagrass photosynthesis, growth and depth distribution. Aquat Bot 27: $15-26$

> Dennison WC, Alberte RS (1985) Role of daily light period in the depth distribution of Zostera marina (eelgrass). Mar Ecol Prog Ser 25:51-61

Dennison WC, Orth RJ, Moore KA, Court Stevenson J and others (1993) Assessing water quality with submersed aquatic vegetation. Bioscience 43:86-94

> DeWitt TJ, Sih A, Sloan Wilson D (1998) Costs and limits of phenotypic plasticity. Trends Ecol Evol 13:77-81

> Duarte CM, Chiscano CL (1999) Seagrass biomass and production: a reassessment. Aquat Bot 65:159-174

- Duarte CM, Marba N, Gacia E, Fourqurean JW, Beggins J, Barron C, Apostolaki ET (2010) Seagrass community metabolism: assessing the carbon sink capacity of seagrass meadows. Global Biogeochem Cycles 24: GB4032

Enríquez S, Pantoja-Reyes NI (2005) Form-function analysis of the effect of canopy morphology on leaf self-shading in the seagrass Thalassia testudinum. Oecologia 145: $234-242$

> Fourqurean JW, Zieman JC (1991) Photosynthesis, respiration and whole plant carbon budget of the seagrass Thalassia testudinum. Mar Ecol Prog Ser 69:161-170

Gacia E, Duarte CM, Middelburg JJ (2002) Carbon and nutrient deposition in a Mediterranean seagrass (Posidonia oceanica) meadow. Limnol Oceanogr 47:23-32

Gallegos CL (1994) Refining habitat requirements of submersed aquatic vegetation: Role of optical models. Estuaries 17:187-199

Gillanders BM (2006) Seagrasses, fish and fisheries. In: Larkum AWD, Orth RJ, Duarte CM (eds) Seagrasses: biology, ecology and conservation. Springer, Dordrecht, p 503-505

Greve TM, Krause-Jensen D (2005) Predictive modelling of eelgrass (Zostera marina) depth limits. Mar Biol 146: 849-858

> Hackney JW, Durako MJ (2004) Size-frequency patterns in morphometric characteristics of the seagrass Thalassia testudinum reflect environmental variability. Ecol Indic $4: 55-71$ 
Harris LA (2006) The virtual seagrass meadow: a simulation of Zostera marina L. linking physiology to population level processes. $\mathrm{PhD}$ thesis, University of Rhode Island.

Hemminga MA (1998) The root/rhizome system of seagrasses: an asset and a burden. J Sea Res 39:183-196

Holmer M, Nielsen SL (1997) Sediment sulfur dynamics related to biomassdensity patterns in Zostera marina (eelgrass) beds. Mar Ecol Prog Ser 146:163-171

Holmer M, Andersen FO, Nielsen SL, Boschker HTS (2001) The importance of mineralization based on sulfate reduction for nutrient regeneration in tropical seagrass sediments. Aquat Bot 71:1-17

Jørgensen BB (1982) Mineralization of organic matter in the sea bed-the role of sulfate reduction. Nature 296: 643-645

Jackson EL, Rowden AA, Attrill MJ, Bossey SJ, Jones MB (2001) The importance of seagrass beds as a habitat for fisheries species. Oceanogr Mar Biol Annu Rev 39: 269-303

Kelaher BP, Van Den Broek J, York PH, Bishop MJ, Booth DJ (2013) Positive responses of a seagrass ecosystem to experimental nutrient enrichment. Mar Ecol Prog Ser 487:15-25

Kenworthy WJ, Gallegos CL, Costello C, Field D, di Carlo G (2014) Dependence of eelgrass (Zostera marina) light requirements on sediment organic matter in Massachusetts coastal bays: implications for remediation and restoration. Mar Pollut Bull 83:446-457

King RJ, Hodgson BR (1995) Tuggerah Lakes system, New South Wales, Australia. In: McComb AJ (ed) Eutrophic shallow estuaries and lagoons. CRC Press, Boca Raton, FL, p 19-29

Kraemer GP, Mazzella L (1996) Nitrogen assimilation and growth dynamics of the Mediterranean seagrasses Posidonia oceanica, Cymodocea nodosa, and Zostera noltii. Proc Rottnest Island Int Seagrass Symp, Perth

Krause-Jensen D, Cartensen J, Nielsen SL, Dalsgaard T, Christensen PB, Fossing H, Rasmussen MB (2011) Sea bottom characteristics affect depth limits of eelgrass Zostera marina. Mar Ecol Prog Ser 425:91-102

Lee KS, Dunton KH (2000a) Dirunal changes in pore water sulfide concentrations in the seagrass Thalassia testudinum beds: the effects of seagrass on sulfide dynamics. J Exp Mar Biol Ecol 255:201-214

> Lee KS, Dunton KH (2000b) Effects of nitrogen enrichment on biomass allocation, growth, and leaf morphology of the seagrass Thalassia testudinum. Mar Ecol Prog Ser 196:39-48

Matheson FE, Schwarz AM (2007) Growth responses of

Editorial responsibility: Just Cebrian,

Dauphin Island, Alabama, USA
Zostera capricorni to estuarine sediment conditions. Aquat Bot 87:299-306

Miller CJ, Campbell SJ, Scudds S (2005) Spatial variation of Zostera tasmanica morphology and structure across an environmental gradient. Mar Ecol Prog Ser 304:45-53

Orth RJ, Carruthers TJB, Dennison WC, Duarte CM and others (2006) A global crisis for seagrass ecosystems. BioScience 56:987-996

> Peralta G, Brun FG, Hernandez I, Vergara JJ, Perez-Llorens JL (2005) Morphometric variations as acclimation mechanisms in Zostera noltii beds. Estuar Coast Shelf Sci 64: 347-356

Perez M, Duarte CM, Romero J, Sand-Jensen K, Alcoverro T (1994) Growth plasticity in Cymodocea nodosa stands: the importance of nutrient supply. Aquat Bot 47:249-264

Ralph PJ, Durako MJ, Enriquez S, Collier CJ, Doblin MA (2007) Impact of light limitation on seagrasses. J Exp Mar Biol Ecol 350:176-193

Schanz A, Asmus H (2003) Impact of hydrodynamics on development and morphology of intertidal seagrasses in the Wadden Sea. Mar Ecol Prog Ser 261:123-134

Sokolik IN (2008) Radiation balance and solar radiation spectrum. In: Jorgensen SE (ed) Global ecology. Academic Press, Amsterdam, p 214-218

Strickland JDH, Parsons TR (1968) A practical handbook of seawater analysis. Fisheries Research Board of Canada Bulletin 167, Ottawa

> van der Heide T, Bouma TJ, van Nes EH, van de Koppel J and others (2010) Spatial self-organized patterning in seagrasses along a depth gradient of an intertidal ecosystem. Ecology 91:362-369

Vermaat JE, Agawin NSR, Fortes DM, Uri J and others (1996) The capacity of seagrasses to survive increased turbidity and siltation: the significance of growth form and light use. Ambio 26:499-504

Watterson EK, Burston JM, Stevens H, Messiter DJ (2010) The hydraulic and morphological response of a large coastal lake to rising sea levels. New South Wales Coastal Conference, Batemans Bay

Waycott M, Duarte CM, Carruthers TJB, Orth RJ and others (2009) Accelerating loss of seagrasses across the globe threatens coastal ecosystems. Proc Natl Acad Sci USA 106:12377-12381

Wicks EC, Koch EW, O'Neil JM, Elliston K (2009) Effects of sediment organic content and hydrodynamic conditions on the growth and distribution of Zostera marina. Mar Ecol Prog Ser 378:71-80

> Zharova N, Sfriso A, Voinov A, Pavoni B (2001) A simulation model for the annual fluctuation of Zostera marina biomass in the Venice lagoon. Aquat Bot 70:135-150

Submitted: August 3, 2015; Accepted: July 7, 2016

Proofs received from author(s): August 24, 2016 